\title{
GÊNESE DE LATOSSOLOS E CAMBISSOLOS DESENVOLVIDOS DE ROCHAS PELÍTICAS DO GRUPO BAMBUÍ - MINAS GERAIS ${ }^{(1)}$
}

\author{
Thiago Torres Costa Pereira ${ }^{(2)}$, João Carlos Ker ${ }^{(3)}$, Carlos \\ Ernesto Gonçalves Reynaud Schaefer ${ }^{(3)}$, Nairam Félix de \\ Barros $^{(3)}$, Júlio César Lima Neves ${ }^{(3)} \&$ Cecília Calhau \\ Almeida ${ }^{(4)}$
}

\begin{abstract}
RESUMO
Considerando a expressividade de Cambissolos (rasos, adensados e siltosos) e Latossolos argilosos e muito argilosos desenvolvidos de rochas pelíticas do Grupo Bambuí, bem como os poucos estudos relacionados à gênese e potencialidade agrícola desses solos, selecionaram-se duas áreas no município de Curvelo-MG, cujo objetivo foi estudar suas características físicas, químicas e mineralógicas. Para isso, foram descritos e coletados perfis de Cambissolos Háplicos (CX), Latossolos Vermelho-Amarelos (LVA) e Latossolos Vermelhos (LV), sendo a TFSA submetida às análises físicas e químicas de rotina, digestão total e sulfúrica, além das análises mineralógicas. Os difratogramas de raios X (DRX) e o índice de intemperismo (Ki) dos CX indicaram menor grau de pedogênese e maior proporção de caulinita e ilita na fração argila (comparativamente aos Latossolos), que coexistem com gibbsita (Gb) e vermiculita com Al-hidroxi entrecamadas (VHE). Nesse caso, a ocorrência de gibbsita não é um bom indicativo de intemperização acentuada. Nos CX, os elevados teores de silte associados à possibilidade de forte ajuste face a face de caulinita/ilita podem ser os principais fatores que interferem na quase ausência de organização estrutural, no adensamento, na pouca percolação de água e na formação de selamento superficial. Na fração argila dos Latossolos foi constatada coexistência de argilominerais e óxidos de Fe e Al muito semelhante à encontrada para os CX, porém com menores proporções de ilita e maiores de gibbsita, inferidos pelos resultados do Ki em torno de 1,4. Ainda que não haja
\end{abstract}

\footnotetext{
(1) Extraído da Dissertação de Mestrado do primeiro autor apresentada ao curso de Pós-Graduação em Solos e Nutrição de Plantas da Universidade Federal de Viçosa - UFV. Recebido para publicação em julho de 2009 e aprovado em maio de 2010.

(2) Doutorando do Departamento de Solos, Universidade Federal de Viçosa - UFV. Av. P.H. Rolfs s/n CEP 36570-000 Viçosa (MG). E-mail: torresthiago@yahoo.com.br

(3) Professor do Departamento de Solos, UFV. E-mails: jcker@ufv.br; carlos.schaefer@ufv.br; nfbarros@ufv.br; julio_n2003@yahoo.com.br

(4) Mestranda do Departamento de Solos, UFV. E-mail: ceciliaufv@yahoo.com.br
} 
diferenciações químicas e físicas marcantes entre os Latossolos, constatou-se em LV magnetização considerável na fração areia, cujo DRX confirmou a presença de magnetita, fato pouco comum em Latossolos desenvolvidos de rochas pelíticas do Grupo Bambuí, mas constatado em estudos anteriores.

Termos de indexação: caulinita, ilita, adensamento, magnetita.

\title{
SUMMARY: GENESIS OF LATOSOLS AND CAMBISOLS DEVELOPED FROM PELITIC ROCKS OF THE BAMBUI GROUP, MINAS GERAIS STATE - BRAZIL
}

\begin{abstract}
The widespread occurrence of Cambisols (shallow, dense and silty) and of clayey and very clayey Latosols is typical of pelitic rocks of the pre-Cambrian Bambui Group landscape, but few studies are focused on the genesis and agricultural potential of these soils. Two areas were selected in Curvelo, state of Minas Gerais, for a detailed study of physical, chemical and mineralogical properties of these soils, to deepen the understanding of the pedogenesis of this area. Soils classified as Haplic Cambisols (Inceptisols), Red-Yellow latosol (Xanthic Haplustox) and Red latosol (Rhodic Haplustox) were selected and sampled, and analyzed for the chemical, mineralogical and physical properties. The XRD data coupled with the calculated weathering index indicated a lower degree of weathering in the shallow Cambisols, with higher proportion of illite and kaolinite in the clay fraction, in comparison to the Latosols, where kaolinite, gibbsite and hydroxy-interlayered vermiculite (HIV) coexist. In this case, the occurrence of gibbsite is not a good indicator of severe weathering. In the shallow Cambisols, higher silt content combined with a face-to-face arrangement of clay particles (kaolinite/illite) may have resulted in poor structural organization, denseness, low water infiltration and soil sealing. In the clay fraction of Latosols, we observed the coexistence of kaolinite/illite and Fe/Al oxides, similarly to the Cambisols, but with much less illite and higher gibbsite contents, as inferred from the results of Ki of around 1.4. Although there are no remarkable physical and chemical differences among Latosols, the Rhodic Latosols displayed considerable magnetization in the sand fraction, where XRD confirmed the presence of magnetite, an uncommon fact in the supposedly magnetite-free pelitic lithologies of the Bambui Group, but reported in previous studies as well.
\end{abstract}

Index terms: kaolinite, illite, density, magnetite.

\section{INTRODUÇÃO}

O Grupo Bambuí, pertencente ao Supergrupo São Francisco, ocupa parte dos Estados de Minas Gerais, Goiás e Bahia. Trata-se de uma área com relativa estabilidade tectônica e sem muita movimentação do relevo, cujas coberturas sedimentares subhorizontalizadas englobam uma sequência de rochas pelito-carbonáticas de idade Neoproterozoica (Neves \& Alkmin, 1993).

Referindo-se à área do Grupo Bambuí que ocorre em Minas Gerais, Almeida (1979) aponta a classe dos Cambissolos Háplicos e dos Latossolos desenvolvidos de rochas pelíticas como sendo unidades pedológicas de ampla ocorrência. Os Cambissolos são caracterizados, de modo geral, como rasos, distróficos, álicos (mas não alíticos) e amarelados. São solos pouco estudados, cujas condições desfavoráveis, tanto físicas (elevados teores de silte e influência da horizontalidade das rochas) quanto mineralógicas (dominantemente caulinítica, com presença de ilita), influenciam no adensamento natural, nas características morfológicas (muito duros quando secos), na restrição à infiltração de água e lixiviação ao longo do perfil, com consequente desaceleração da frente de intemperismo.

Os Latossolos são de baixa fertilidade natural (distróficos), argilosos ou muito argilosos, cuja granulometria mais fina do material de origem e mineralogia da fração argila, dominantemente caulinítica, favorecem a formação de consistência dura quando secos e de adensamento natural, em algumas situações. Além da caulinita, apontada por vários autores como o mineral mais expressivo na fração argila da maioria dos Latossolos brasileiros (Resende et al., 2005; Schaefer et al., 2008), ocorrem goethita, hematita e gibbsita, em proporções no solo que dependem de variações do material de origem, da intensidade de intemperismo e das condições de drenagem. Menos comumente, argilominerais 2:1 são também encontrados em quantidades pequenas, como vermiculita com Al-hidroxi entrecamadas (VHE) e ilita, geralmente em menores proporções nos Latossolos em relação aos Cambissolos. 
Nesse caso, a coexistência de VHE e gibbsita contraria o efeito "anti-gibbsítico" proposto por Jackson (1964). Resultados condizentes com essa observação foram apontados por Rodrigues Netto (1996), que detectou traços de VHE e ilita mesmo em Latossolos gibbsíticos profundamente alterados e com índice de intemperismo (Ki) muito baixo. A coexistência de ilita e gibbsita também foi observada por Almeida (1979) em Cambissolos desenvolvidos de rochas pelíticas com $\mathrm{Ki}>2,0$.

Na fração grosseira (silte e areia) dos Latossolos e Cambissolos desenvolvidos de rochas pelíticas, de modo geral, prevalece o mineral quartzo, com pequenas quantidades de muscovita e apenas traços de feldspato - reflexo da maior capacidade de alteração deste último mineral. Na fração areia dos LV foi constatada a presença de magnetita, fato também observado por Viana et al. (2006) em alguns LV do Grupo Bambuí.

Assim, considerando a expressividade de Cambissolos e Latossolos desenvolvidos de rochas pelíticas do Grupo Bambuí, selecionaram-se duas áreas no município de Curvelo-MG, com o objetivo de estudar características físicas, químicas e mineralógicas desses solos capazes de auxiliar na compreensão dos processos pedogenéticos atuantes.

\section{MATERIAL E MÉTODOS}

O presente trabalho foi realizado nas fazendas Olhos d'Água (1.965 ha) e Cachoeira (2.649 ha), localizadas no município de Curvelo, região central do Estado de Minas Gerais. Foram descritos e coletados 13 perfis de solos, conforme Santos et al. (2005), classificados como Cambissolos Háplicos - CX (perfis P1, P4, P6, P9, P12 e P13), Latossolos Vermelho-Amarelos - LVA (perfis P2, P3, P5 e P7) e Latossolos Vermelhos - LV (perfis P8, P10 e P11) (Figura 1). A classificação de todos os perfis de solos, em nível de subgrupo (Embrapa, 2006), encontra-se no quadro 1.

De acordo com a classificação de Köppen, o clima na região é do tipo Aw, tropical de savana. Apresenta temperatura média anual de $22^{\circ} \mathrm{C}$ e precipitação pluvial média de $1.300 \mathrm{~mm}$, existindo dois períodos predominantes: verão úmido e inverno seco (Strahler \& Strahler, 2002).

A região possui embasamento rochoso da Formação Três Marias, pertencente ao Grupo Bambuí, constituída de arcózios finos, ardósias e siltitos micáceos aluminosos (CPRM, 1984).

As características geomorfológicas regionais, conforme observações de King (1956), correspondem ao Ciclo de Denudação Velhas, que remonta ao Terciário Superior. Os Latossolos ocorrem dominantemente nos terraços elevados, em relevo plano/suave ondulado, sob vegetação de Cerrado stricto sensu. Os CX ocorrem principalmente em relevo suave ondulado/ondulado (morros testemunhos), com predominância de campo Cerrado.

Nas análises físicas, foram determinadas a composição granulométrica (Ruiz, 2005), a condutividade hidráulica, a densidade do solo (método do anel volumétrico) e a argila dispersa em água e calculado o grau de floculação (Embrapa, 1997). Nas análises químicas, procedeu-se à determinação de: $\mathrm{pH}$ em água e $\mathrm{KCl} 1 \mathrm{~mol} \mathrm{~L}^{-1}$; $\mathrm{CO}$ (Yeomans \& Bremner, 1988); $\mathrm{P}$ disponível, $\mathrm{Na}^{+}$e $\mathrm{K}^{+}$, após extração com $\mathrm{HCl}$ $0,5 \mathrm{~mol} \mathrm{~L}^{-1}+\mathrm{H}_{2} \mathrm{SO}_{4} 0,0125 \mathrm{~mol} \mathrm{~L}^{-1}$ (Mehlich-1); $\mathrm{Ca}^{2+}$

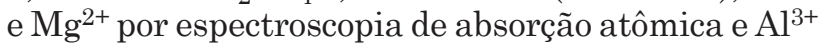
por titulometria, após serem extraídos com $\mathrm{KCl}$ $1 \mathrm{~mol} \mathrm{~L}^{-1}$; e acidez potencial $(\mathrm{H}+\mathrm{Al})$ por titulometria, após extração com $\mathrm{Ca}\left(\mathrm{CH}_{3} \mathrm{COO}_{2}\right) 0,5 \mathrm{~mol} \mathrm{~L}^{-1}$ a pH 7,0. Todas as análises químicas foram baseadas em Embrapa (1997).

A digestão com $\mathrm{H}_{2} \mathrm{SO}_{4}$ 9,0 mol L-1 da TFSA (moída e passada em peneira com malha de $0,25 \mathrm{~mm}$ ) foi realizada segundo Embrapa (1997). Foram determinados por espectrofotometria de emissão ótica de plasma indutivamente acoplado os seguintes elementos: $\mathrm{Al}, \mathrm{Fe}$ e Ti; e $\mathrm{Si}$, por espectrofotometria UV-Visível no comprimento de onda de $660 \mathrm{~nm}$ (Korndörfer \& Nolla, 2004).

A digestão total da TFSA (moída e passada em peneira com malha de $0,25 \mathrm{~mm}$ ) com $\mathrm{HNO}_{3}$ e $\mathrm{HF}$, ambos concentrados, foi realizada com aquecimento em forno de micro-ondas (DGT 100), conforme método EPA 3052 (1996). Foram determinados por espectrofotometria de emissão ótica de plasma indutivamente acoplado os teores totais de $\mathrm{Ca}, \mathrm{Mg}, \mathrm{K}$, $\mathrm{Fe}, \mathrm{Al}, \mathrm{Mn}$ e P.

Os minerais da TFSA foram identificados por difratometria de raios X (DRX). Na fração argila, foram realizados os seguintes tratamentos: desferrificação com ditionito-citrato-bicarbonato (DCB) (Mehra \& Jackson, 1960); saturação com KCl 1,0 mol L-1 ; e aquecimento em mufla a $550{ }^{\circ} \mathrm{C}$ por $3 \mathrm{~h}$. Foi utilizado difratômetro Rigaku Radiation Shield, empregando-se radiação de $\mathrm{CoK} \alpha$ na faixa de 4 a 45 ${ }^{\circ} 2 \theta$ (lâminas naturais) e 5 a $30^{\circ} 2 \theta$ (lâminas com tratamentos), cujos intervalos foram de $0,02{ }^{\circ} 2 \theta$ a 1 passo $\mathrm{s}^{-1}$, com tensão de $40 \mathrm{kV}$ e corrente de $30 \mathrm{~mA}$.

Nódulos e, ou, concreções ferruginosas constatados na fração areia e, em menor proporção, no cascalho foram moídos e passados em peneira com malha de $0,25 \mathrm{~mm}$, para extrações com: DCB 0,3 $\mathrm{mol} \mathrm{L}^{-1}$ (seis extrações sucessivas) (Mehra \& Jackson, 1960); e oxalato ácido de amônio $0,2 \mathrm{~mol} \mathrm{~L}^{-1}$ a $\mathrm{pH} 3,0$ (McKeague \& Day, 1966). Em ambos os métodos, o Fe foi determinado por espectrofotometria de absorção atômica. 


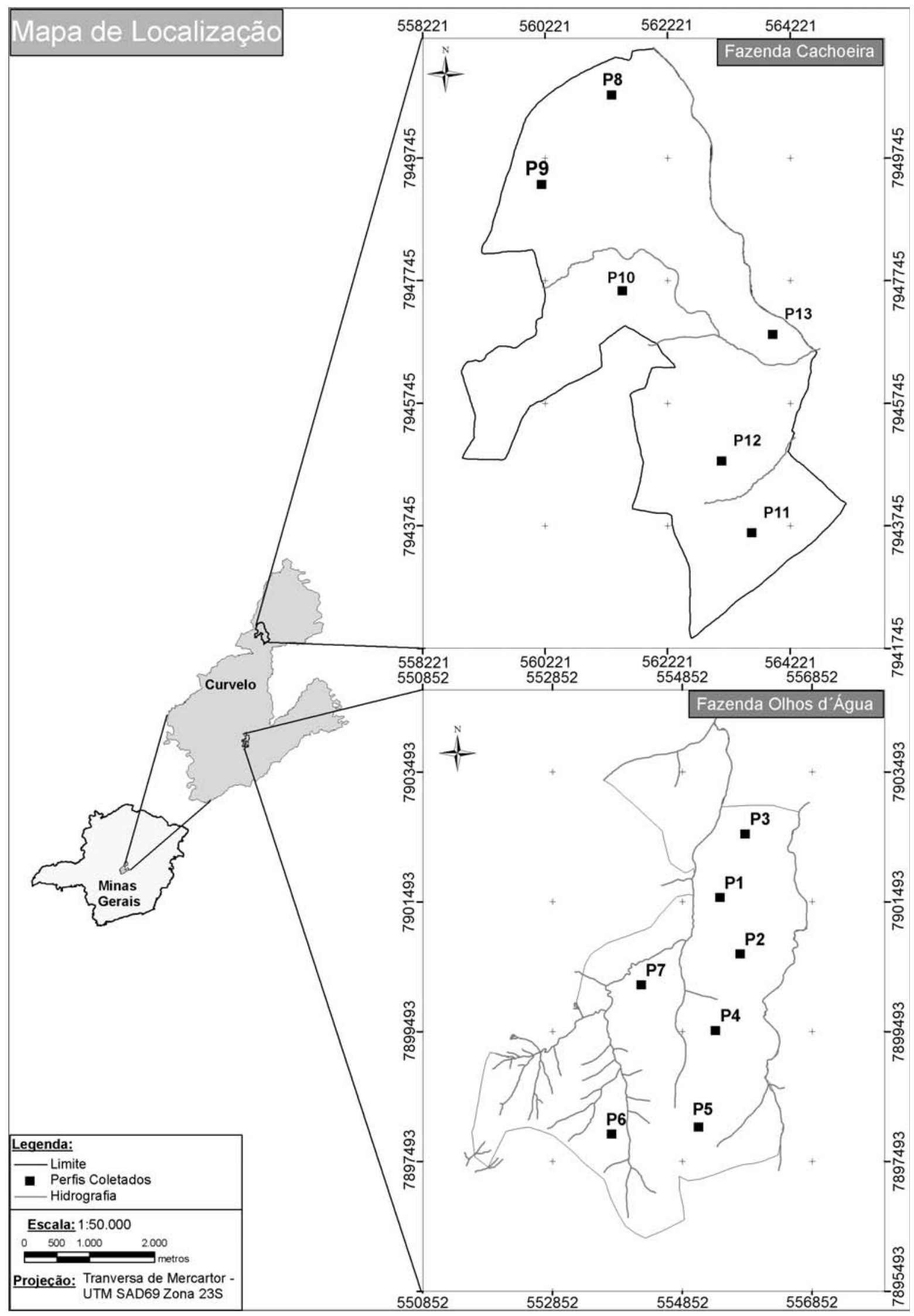

Figura 1. Localização das áreas trabalhadas e dos perfis coletados. 
Quadro 1. Características físicas e químicas dos solos estudados

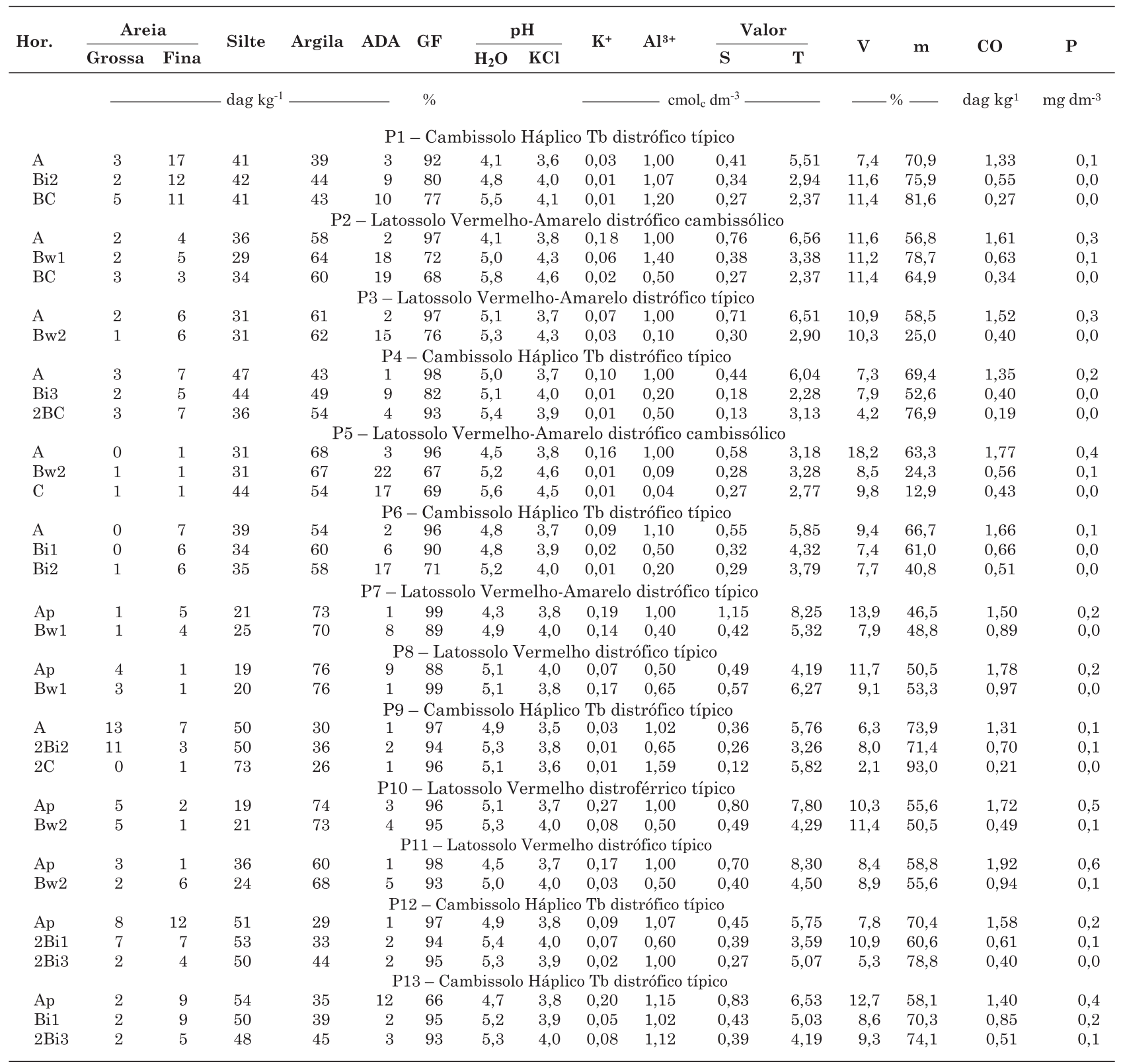

\section{RESULTADOS E DISCUSSÃO}

\section{Caracterização morfológica}

As características morfológicas apresentaram diferenciações em relação à cor, estrutura, consistência e profundidade. Os CX apresentaram matizes de 10YR e 7,5YR nos horizontes $\mathrm{A}$ e $\mathrm{Bi}$, respectivamente. A estrutura dos horizontes $\mathrm{Bi}$, em uma primeira observação, parece maciça. Entretanto, com exame mais detalhado, observa-se a ocorrência de blocos subangulares pequenos e médios, fracamente desenvolvidos. O horizonte $\mathrm{C}$ apresenta-se maciço, às vezes refletindo os estratos horizontalizados do material de origem (rochas pelíticas). Todos os CX apresentam consistência dura ou muito dura quando secos e são solos pouco espessos, nos quais o solum raramente ultrapassa $100 \mathrm{~cm}$.

Os horizontes Bw dos LVA apresentam estrutura fraca pequena média em blocos subangulares e consistência dura quando secos e friável a firme quando úmidos.

Os horizontes Bw dos LV apresentam matizes 10R (P10) e 2,5YR, com estruturas que variam de granular a blocos subangulares e consistência ligeiramente dura 
quando secos e friável quando úmidos. Tanto os LV como os LVA são profundos e apresentam linhas de pedra abaixo de $150 \mathrm{~cm}$ de profundidade. Em todas as observações realizadas em solos das áreas, é característica a consistência seca mais dura no Bw dos LVA do que nos LV.

\section{Caracterização física}

Os teores de silte dos CX são, em média, de 47 dag $\mathrm{kg}^{-1}$ (Quadro 1), o que é condizente com a constituição siltosa do material de origem. Resultados de silte + argila ultrapassam $80 \%$ em todos os perfis . Somatórios semelhantes foram apontados por Achá Panoso et al. (1978) e Almeida (1979) para CX derivados de rochas pelíticas do Grupo Bambuí, os quais destacaram a grande influência de materiais finos, principalmente silte, no adensamento desses solos. Resultados elevados de densidade do solo (Ds) parecem corroborar essa explicação, além de repercutir sobremaneira na dificuldade de percolação de água em virtude da baixa condutividade hidráulica (Ko) observada (Quadro 2), provocando, principalmente nos $\mathrm{CX}$, dificuldade de avanço da frente de intemperismo e alteração do perfil (sugestiva pela relação silte/argila em torno de 1,2). Nesse caso, provavelmente a baixa capacidade de recarga hídrica dos CX, associada à dificuldade de entalhamento dos rios (pela horizontalidade dos estratos rochosos), que são pouco profundos, sejam as principais razões de secagem dos pequenos cursos d'água no período de estiagem (inverno).

$\mathrm{O}$ adensamento, provavelmente relacionado aos elevados teores de silte e ao predomínio da caulinita na fração argila, além de ilita (possibilidade de ajuste face a face destes argilominerais), associado a uma

\section{Quadro 2. Densidade do solo e condutividade hidráulica}

\begin{tabular}{|c|c|c|c|c|}
\hline Amostra & Solo ${ }^{(1)}$ & Profundidade & $\mathrm{Ds}^{(2)}$ & $\mathrm{Ko}^{(3)}$ \\
\hline & & $\mathrm{cm}$ & $\mathrm{g} \mathrm{cm}^{-3}$ & $\mathrm{~cm} \mathrm{~h}^{-1}$ \\
\hline Perfil P1 & CXbd & $10-15$ & 1,48 & 0,42 \\
\hline Perfil P2 & LVAd & $5-10$ & 1,27 & 1,13 \\
\hline Perfil P3 & LVAd & $40-45$ & 1,33 & 0,54 \\
\hline Perfil P4 & CXbd & $10-15$ & 1,35 & 0,45 \\
\hline Extra $1^{(4)}$ & CXbd & $25-30$ & 1,25 & 1,64 \\
\hline Extra $2^{(4)}$ & LVAd & $5-10$ & 1,28 & 0,88 \\
\hline Extra $3^{(4)}$ & $\mathrm{LVd}$ & $5-10$ & 1,01 & 12,91 \\
\hline Perfil P8 & $\mathrm{LVd}$ & $5-10$ & 1,20 & 4,67 \\
\hline Perfil P9 & $\mathrm{CXbd}$ & $5-10$ & 1,45 & 0,46 \\
\hline Perfil P11 & LVd & $5-10$ & 1,47 & 0,87 \\
\hline Perfil P12 & $\mathrm{CXbd}$ & $5-10$ & 1,45 & 0,22 \\
\hline
\end{tabular}

(1) CXbd: Cambissolo Háplico Tb distrófico; LVAd: Latossolo Vermelho-Amarelo distrófico; LVd: Latossolo Vermelho distrófico. (2) Densidade do solo (anel volumétrico). ${ }^{(3)}$ Condutividade hidráulica em meio saturado. ${ }^{(4)}$ Coletadas na Faz. Olhos d'Água. Obs.: o trabalho foi realizado com solos e horizontes diferentes, não sendo procedente padronizar profundidade de coleta. topografia mais declivosa e horizontalidade das rochas, cria para os CX uma condição de predisposição ao selamento superficial e acentuada erosão laminar. Estudos efetuados por Mermut et al. (1995) e Lado \& Ben-Hur (2004) comprovaram que solos contendo dominantemente caulinita e ilita na fração argila são suscetíveis ao selamento superficial. Todos esses fatos, potencializados pela baixa fertilidade natural (Quadro 1) e baixa profundidade efetiva (pequeno armazenamento de água), dificultam a ciclagem de nutrientes, configurando grandes áreas com cobertura parcial do solo pela vegetação natural (campo Cerrado), o que reforça a maior erodibilidade e formação de selamento superficial pela ação muitas vezes direta da chuva sobre o solo.

Os LVA possuem teores de argila que variam de 54 a $73 \mathrm{dag} \mathrm{kg}^{-1}$, e teores de silte, em média, de 31 dag kg-1 (Quadro 1). Mesmo com teores relativamente elevados de silte, a relação silte/argila em torno de 0,5 para esses solos permite o enquadramento na definição de Bw pelo SiBCS (Embrapa, 2006), ainda que seja sugestivo algo intermediário com Cambissolos. Comparativamente, os LV possuem teores de argila variando de 60 a $76 \mathrm{dag} \mathrm{kg}^{-1}$, e teores de silte, em média, de 23 dag $\mathrm{kg}^{-1}$, sendo a relação silte/ argila em torno de 0,3 sugestiva de maior intemperização. É possível, nestes solos, que parte do silte deva-se a agregados argilosos de difícil dispersão, o que de certa forma pode explicar a maior friabilidade dos LV.

\section{Caracterização química}

Os Cambissolos Háplicos estudados são todos ácidos e distróficos, com teores de $\mathrm{Al}^{3+}$ em torno de $0,90 \mathrm{cmol}_{\mathrm{c}} \mathrm{dm}^{-3}$ (Quadro 1), não suficientes para o enquadramento no caráter alumínico do atual SiBCS (Embrapa, 2006). Achá Panoso et al. (1978) encontrou, em alguns Cambissolos desenvolvidos de sedimentos argilo-siltosos do Grupo Bambuí em região próxima à do presente estudo, solos que atualmente se enquadrariam como Cambissolos Háplicos alumínicos típicos, o que indica a possibilidade de que em algumas situações esses solos ocorram na área do presente estudo.

Os resultados de $\mathrm{pH}$ em $\mathrm{H}_{2} \mathrm{O}$ maiores que aqueles obtidos com KCl $1 \mathrm{~mol} \mathrm{~L}^{-1}$ indicam o predomínio de cargas negativas em todos os Latossolos e Cambissolos estudados.

Teores muito baixos de $\mathrm{K}^{+}$sugerem que ele, ainda que presente nos Latossolos e Cambissolos deste estudo (solos desenvolvidos de substrato pelítico), encontrase na forma não trocável. Teores semelhantes de $\mathrm{K}^{+}$, em torno de $0,03 \mathrm{cmol}_{\mathrm{c}} \mathrm{dm}^{-3}$, foram constatados por Almeida (1979) em solos desenvolvidos de rochas pelíticas do Grupo Bambuí, sendo esses teores pouco menores que os encontrados por Achá Panoso et al. (1978) também para solos em áreas próximas à do presente estudo.

Teores de $\mathrm{P}$ extraído pelo Mehlich- 1 também são muito baixos, o que é condizente com os encontrados 
por Almeida (1979), que representam, segundo esse autor, a principal limitação nutricional dos solos desenvolvidos de rochas pelíticas. Os teores de carbono orgânico (CO) são, em média, de 1,44 dag kg-1 para o horizonte A dos CX, seguindo praticamente a mesma ordem de grandeza daqueles encontrados para os Latossolos.

Em relação aos Latossolos Vermelho-Amarelos e Latossolos Vermelhos, todos são ácidos, distróficos e, de modo geral, álicos, refletindo, assim como nos Cambissolos do presente estudo, a pobreza do material pelítico e a influência deste nos teores de $\mathrm{Al}^{3+}$.

\section{Digestão sulfúrica e total}

Teores de $\mathrm{Fe}_{2} \mathrm{O}_{3}$ são, em média, menores para os CX (8,8 dag kg-1), intermediários para os LVA (12,1 dag kg-1) e maiores para os LV (16,4 dag kg-1), com destaque para o perfil P10, cujos teores acima de 22 dag kg-1 (Quadro 3) permitiram classificá-lo como férrico (Embrapa, 2006) - fato ainda não observado em Latossolos na área de domínio das rochas pelíticas do Grupo Bambuí. Os teores diferenciados de $\mathrm{Fe}_{2} \mathrm{O}_{3}$, associados à mineralogia dos solos, sugerem variações na composição do material de origem (ou deposição de material mais rico em Fe sobre as rochas do Bambuí),

Quadro 3. Resultados de digestão sulfúrica e total em TFSA dos solos estudados

\begin{tabular}{|c|c|c|c|c|c|c|c|c|c|c|c|c|c|}
\hline \multirow[b]{2}{*}{ Horizonte } & \multicolumn{5}{|c|}{ Digestão sulfúrica } & \multirow[b]{2}{*}{$\frac{\mathrm{Al}_{2} \mathrm{O}_{3}}{\mathrm{Fe}_{2} \mathrm{O}_{3}}$} & \multicolumn{7}{|c|}{ Digestão total } \\
\hline & $\mathrm{SiO}_{2}$ & $\mathrm{Al}_{2} \mathrm{O}_{3}$ & $\mathrm{Fe}_{2} \mathrm{O}_{3}$ & $\mathrm{TiO}_{2}$ & $\mathbf{K i}$ & & $\mathrm{CaO}$ & MgO & $\mathbf{K}_{2} \mathbf{O}$ & \multirow{2}{*}{ 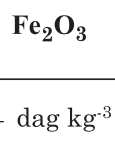 } & \multirow[t]{2}{*}{$\mathrm{Al}_{2} \mathbf{O}_{3}$} & \multirow[t]{2}{*}{ MnO } & $\mathbf{P}_{2} \mathbf{O}_{5}$ \\
\hline & $\longrightarrow$ & - dag & -3 & 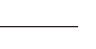 & & & 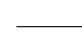 & 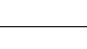 & & & & & \\
\hline \multicolumn{14}{|c|}{ P1 - Cambissolo Háplico Tb distrófico típico } \\
\hline $\mathrm{A}$ & 18,6 & 15,6 & 8,4 & 0,69 & 2,0 & 2,9 & 1,44 & 0,55 & 3,38 & 8,95 & 20,75 & 0,05 & 0,11 \\
\hline $\mathrm{Bi} 2$ & 17,5 & 16,7 & 8,3 & 0,72 & 1,8 & 3,2 & 1,80 & 0,23 & 3,53 & 8,56 & 16,74 & 0,01 & 0,08 \\
\hline $\mathrm{BC}$ & 20,2 & 16,6 & 8,5 & 0,72 & 2,1 & 3,1 & 0,78 & 0,28 & 2,94 & 8,52 & 17,65 & 0,10 & 0,09 \\
\hline \multicolumn{14}{|c|}{ P2 - Latossolo Vermelho-Amarelo distrófico cambissólico } \\
\hline $\mathrm{A}$ & 22,4 & 26,7 & 11,3 & 0,76 & 1,4 & 3,7 & 1,44 & 0,51 & 2,58 & 12,21 & 28,80 & 0,09 & 0,14 \\
\hline Bw1 & 23,7 & 28,5 & 11,3 & 0,78 & 1,4 & 4,0 & 2,11 & 0,65 & 3,12 & 11,52 & 30,27 & 0,05 & 0,09 \\
\hline $\mathrm{BC}$ & 22,7 & 26,9 & 14,2 & 0,95 & 1,4 & 3,0 & 2,66 & 0,41 & 2,49 & 15,76 & 28,34 & 0,18 & 0,08 \\
\hline & & & & P3 - La & solo I & melho-A & arelo d & rófico $\mathrm{t}$ & pico & & & & \\
\hline A & 24,5 & 28,8 & 9,9 & 0,74 & 1,4 & 4,5 & 1,44 & 0,51 & 2,58 & 11,82 & 29,76 & 0,05 & 0,09 \\
\hline Bw2 & 23,4 & 26,1 & 9,1 & 0,66 & 1,5 & 4,5 & 1,25 & 0,41 & 2,72 & 10,15 & 27,70 & 0,06 & 0,05 \\
\hline & & & & $\mathrm{P} 4-$ & mbis & Háplico & $\Gamma \mathrm{b}$ distı & ico típic & & & & & \\
\hline A & 19,2 & 16,5 & 10,4 & 0,65 & 2,0 & 2,5 & 1,05 & 0,17 & 3,58 & 11,32 & 16,12 & 0,09 & 0,05 \\
\hline $\mathrm{Bi} 3$ & 23,1 & 20,8 & 10,0 & 0,77 & 1,9 & 3,3 & 0,60 & 0,18 & 3,88 & 11,50 & 21,22 & 0,08 & 0,03 \\
\hline $2 \mathrm{BC}$ & 26,0 & 20,7 & 10,1 & 0,73 & 2,1 & 3,2 & 0,94 & 0,35 & 3,69 & 12,95 & 24,47 & 0,06 & 0,09 \\
\hline & & & & - Latos & Ver & lho-Ama & lo distr & ico cam & issólico & & & & \\
\hline $\mathrm{A}$ & 23,7 & 30,1 & 13,1 & 0,78 & 1,3 & 3,6 & 1,44 & 0,80 & 2,48 & 13,85 & 33,14 & 0,06 & 0,06 \\
\hline Bw2 & 24,4 & 27,9 & 13,1 & 0,75 & 1,5 & 3,3 & 2,57 & 0,61 & 1,93 & 13,18 & 31,48 & 0,05 & 0,07 \\
\hline $\mathrm{C}$ & 24,2 & 29,4 & 14,7 & 0,88 & 1,4 & 3,1 & 3,40 & 0,66 & 2,30 & 14,75 & 32,73 & 0,08 & 0,07 \\
\hline & & & & P6- & mbis & o Háplico & Tb dist & ico típic & & & & & \\
\hline $\mathrm{A}$ & 26,8 & 22,9 & 9,1 & 0,80 & 2,0 & 4,0 & 1,93 & 0,58 & 4,06 & 10,01 & 24,53 & 0,05 & 0,07 \\
\hline $\mathrm{Bi} 2$ & 24,6 & 23,7 & 9,1 & 0,78 & 1,8 & 4,1 & 1,93 & 0,30 & 2,20 & 10,29 & 25,21 & 0,03 & 0,05 \\
\hline & & & & $\mathrm{P} 7-\mathrm{L}$ & solo & melho-A & narelo o & trófico & pico & & & & \\
\hline Ap & 19,1 & 23,6 & 11,9 & 0,97 & 1,4 & 3,1 & 2,28 & 0,63 & 1,20 & 12,82 & 25,79 & 0,05 & 0,07 \\
\hline Bw1 & 18,1 & 27,1 & 12,1 & 0,94 & 1,1 & 3,5 & 1,40 & 0,30 & 1,28 & 12,50 & 29,02 & 0,06 & 0,06 \\
\hline & & & & & atos: & erme & distró & o típice & & & & & \\
\hline Ap & 23,5 & 28,8 & 16,7 & 1,13 & 1,4 & 2,7 & 1,12 & 0,18 & 0,99 & 19,79 & 31,01 & 0,06 & 0,09 \\
\hline Bw1 & 23,0 & 28,1 & 15,8 & 1,04 & 1,4 & 2,8 & 2,41 & 0,40 & 1,43 & 19,32 & 32,44 & 0,06 & 0,08 \\
\hline & & & & P9- & mbis & o Háplicc & $\mathrm{Tb}$ dist & fico típi & & & & & \\
\hline $\mathrm{A}$ & 20,9 & 17,4 & 6,8 & 0,61 & 2,0 & 4,0 & 1,26 & 0,15 & 3,02 & 7,39 & 19,74 & 0,04 & 0,05 \\
\hline $2 \mathrm{Bi} 2$ & 17,0 & 14,3 & 8,2 & 0,65 & 2,0 & 2,7 & 0,85 & 0,38 & 3,22 & 8,21 & 17,84 & 0,03 & 0,05 \\
\hline $2 \mathrm{C}$ & 27,6 & 22,1 & 9,1 & 0,72 & 2,1 & 3,8 & 1,06 & 0,45 & 3,52 & 9,41 & 23,32 & 0,03 & 0,04 \\
\hline & & & & P10 & atoss & Vermelh & distrof & rico típi & & & & & \\
\hline Ap & 24,4 & 27,1 & 22,3 & 0,96 & 1,5 & 1,9 & 3,29 & 0,41 & 1,87 & 23,68 & 29,65 & 0,08 & 0,12 \\
\hline Bw2 & 24,5 & 29,8 & 22,6 & 0,95 & 1,4 & 2,1 & 2,71 & 0,51 & 1,55 & 24,42 & 31,44 & 0,09 & 0,09 \\
\hline & & & & & Lato & lo Verme & o distró & o típico & & & & & \\
\hline Ap & 18,4 & 23,7 & 10,4 & 0,90 & 1,3 & 3,6 & 1,86 & 0,56 & 0,81 & 13,25 & 25,51 & 0,04 & 0,06 \\
\hline Bw2 & 22,0 & 25,9 & 10,6 & 0,87 & 1,4 & 3,8 & 2,29 & 0,45 & 0,88 & 13,07 & 29,40 & 0,04 & 0,05 \\
\hline & & & & $\mathrm{P} 12$ & ambi & lo Háplic & Tb distr & ico típicc & & & & & \\
\hline Ap & 15,2 & 13,2 & 10,9 & 0,75 & 2,0 & 1,9 & 2,57 & 0,55 & 2,47 & 11,18 & 18,63 & 0,06 & 0,05 \\
\hline $2 \mathrm{Bi} 1$ & 19,1 & 18,7 & 9,4 & 0,71 & 1,7 & 3,1 & 1,90 & 0,27 & 2,10 & 9,81 & 19,63 & 0,04 & 0,03 \\
\hline $2 \mathrm{Bi} 3$ & 25,4 & 21,8 & 9,7 & 0,75 & 2,0 & 3,5 & 0,97 & 0,58 & 2,32 & 9,95 & 24,71 & 0,04 & 0,04 \\
\hline & & & & & Cambi & lo Hápli & $\mathrm{Tb}$ distr & ico típic & & & & & \\
\hline Ap & 15,9 & 13,9 & 5,7 & 0,62 & 1,9 & 3,8 & 1,94 & 0,48 & 1,23 & 6,21 & 21,96 & 0,04 & 0,07 \\
\hline $2 \mathrm{Bi} 3$ & 21,3 & 19,5 & 7,6 & 0,69 & 1,9 & 4,0 & 3,74 & 0,38 & 1,26 & 7,71 & 24,37 & 0,04 & 0,07 \\
\hline
\end{tabular}


havendo maior distinção no material relacionado aos LV. O menor valor para a relação molecular $\mathrm{Al}_{2} \mathrm{O}_{3} /$ $\mathrm{Fe}_{2} \mathrm{O}_{3}$ foi 1,9 , indicando predomínio das formas de alumínio para todos os perfis estudados. De acordo com Melo (1998), essa constatação indica maior presença das micas dioctaedrais em detrimento das micas trioctaedrais, o que reforça a presença da ilita na fração argila dos solos estudados.

Foram observados teores muito baixos de $\mathrm{TiO}_{2}$, ressaltando que esses óxidos apresentam teores um pouco maiores nos Latossolos, principalmente os LV, em relação aos Cambissolos Háplicos. Nos perfis P2, $\mathrm{P} 4, \mathrm{P} 5, \mathrm{P} 9$ e $\mathrm{P} 13$, as variações nos teores de $\mathrm{TiO}_{2}$ em maiores profundidades sugerem a ocorrência de descontinuidade litológica.

Teores menores de $\mathrm{SiO}_{2}$, quando comparados com os de $\mathrm{Al}_{2} \mathrm{O}_{3}$ em todos os perfis dos Latossolos, revelaram maior dessilicificação para essas classes de solos, confirmada pela mineralogia, cujos valores de Ki, de modo geral, em torno de 1,4, indicam mineralogia dominantemente caulinítica na fração argila, com presença de ilita e, em menor quantidade, gibbsita. Para esses solos, os valores baixos de Ki associados aos resultados de CTCr $<17 \mathrm{cmol}_{\mathrm{c}} \mathrm{dm}^{-3}$, baixa relação textural e relação silte/argila $\leq 0,5$ atestam maior alteração pedogenética, comparativamente aos CX, cujos valores de Ki foram, em média, de 2,0. Os resultados de Ki são condizentes com os obtidos por Achá Panoso et al. (1978) e Almeida (1979) para solos desenvolvidos de rochas pelíticas do Grupo Bambuí.

Nos CX, a mineralogia é dominantemente caulinítica/ilítica, confirmada pelos resultados de DRX, com valores de CTCr chegando no máximo a $22 \mathrm{cmol}_{\mathrm{c}} \mathrm{dm}^{-3}$. Resultados de Ki mais elevados, de 2,4, foram encontrados por Achá Panoso et al. (1978) para CX originados de filito do Grupo Bambuí. Pelo fato de a presença dos picos em 1,43 e 1,13 nm (DRX) estar relacionada à VHE (vide mineralogia), é sugestivo que os polímeros de alumínio nas entrecamadas desse argilomineral tenham contribuído para resultados de $\mathrm{Ki}$, ainda que elevados, mais baixos que os encontrados por Achá Panoso et al. (1978). Essa constatação foi feita por Ker (1988) em trabalho com solos brunos subtropicais, nos quais a presença de VHE provavelmente influenciou no abaixamento do Ki.

Os teores dos óxidos totais obtidos pela digestão da TFSA encontram-se no quadro 3. Os teores totais de $\mathrm{K}_{2} \mathrm{O}$ foram, em média, de 3, 2 e 1 dag kg-1 para CX, LVA e LV, respectivamente. De acordo com Ernani et al. (2007), teores totais de $\mathrm{K}_{2} \mathrm{O}$ normalmente encontrados para solos desenvolvidos de rochas pelíticas estão em torno de $3,2 \mathrm{dag} \mathrm{kg}^{-1}$, o que condiz com os encontrados, principalmente nos Cambissolos deste trabalho, justamente nos quais os minerais micáceos (muscovita/ilita) parecem ocorrer em maior quantidade.

Outra fonte de contribuição do K total no solo, mesmo que muito pequena, pode estar relacionada à caulinita (Melo, 1998), devido à sua grande presença, sobretudo nos CX. Estudos apontados por Melo (1998) evidenciaram presença de $\mathrm{K}$ em caulinitas, o que, segundo Sparks (1987), pode estar relacionado tanto à presença de cargas negativas decorrentes de substituição isomórfica, quanto à existência de camadas oclusas de micas na estrutura do mineral, já que pouca caulinita pura é encontrada em solos ou mesmo em minas de caulim.

Em relação à liberação de K para a solução do solo, a concentração crítica na qual esta é inibida varia de $6 \times 10^{-3} \mathrm{a} 4 \times 10^{-2} \mathrm{cmol}_{\mathrm{c}} \mathrm{dm}^{-3}$ para micas trioctaedrais em soluções diluídas e abaixo de $3 \times 10^{-4} \mathrm{cmol}_{\mathrm{c}} \mathrm{dm}^{-3}$ para muscovita (Martin \& Sparks, 1983). Nos solos estudados, em todos os horizontes os menores teores de $\mathrm{K}^{+}$foram de $1 \times 10^{-2} \mathrm{cmol}_{\mathrm{c}} \mathrm{dm}^{-3}$, sendo muito superiores aos apresentados para a muscovita. Nesse caso, para que este mineral libere $\mathrm{K}$, os teores disponíveis deste íon devem ser muito pequenos, fato que explica a grande diferença entre $\mathrm{K}^{+}$e $\mathrm{K}$ total. Esse fato condiz com estudos realizados por Sparks \& Huang (1985), cujas observações são de que a maior parte dos teores totais de $\mathrm{K}$ dos solos está na fase mineral.

Teores totais de $\mathrm{Fe}_{2} \mathrm{O}_{3}$ foram menores que os de $\mathrm{Al}_{2} \mathrm{O}_{3}$ (Quadro 3), seguindo a mesma tendência desses óxidos extraídos pela digestão sulfúrica. Uma comparação entre os métodos de extração (digestão total e sulfúrica) revela maiores teores quando a digestão foi total, apesar de em alguns horizontes os teores apresentarem-se muito próximos, indicando que esses óxidos encontram-se em grande parte na fração argila dos solos. Teores totais de $\mathrm{Fe}_{2} \mathrm{O}_{3}$ em torno de 2,30 dag kg-1 encontrados por Chiodi Filho et al. (2003) para ardósias próximo à região de Curvelo são inferiores aos encontrados nos solos do presente estudo, o que sugere deposição por desmonte de superfícies mais elevadas do entorno do Grupo Bambuí, concentração relativa de Fe na rocha, ou mesmo concentração residual nos solos.

Teores totais muito baixos de $\mathrm{P}_{2} \mathrm{O}_{5}$, em torno de $0,07 \mathrm{dag} \mathrm{kg}^{-1}$, evidenciam a deficiência das fontes de reserva dos solos estudados para esse óxido. Teores totais, em torno de 0,14 dag $\mathrm{kg}^{-1}$ (Chiodi Filho et al., 2003), encontrados em ardósias localizadas em áreas próximas à do presente estudo confirmam a carência desse nutriente no material de origem.

\section{Características mineralógicas}

Os difratogramas de raios $\mathrm{X}$ (DRX), com picos em $0,72,0,45$ e $0,36 \mathrm{~nm}$, indicam presença de caulinita, provavelmente $\mathrm{o}$ argilomineral que prevalece na fração argila de todos os solos (Figura 2). Picos em 1,00, $0,50,0,45,0,33$ e $0,26 \mathrm{~nm}$ indicam presença de ilita. Este argilomineral parece destacar-se na fração argila dos CX, talvez como argilomineral subdominante, sendo a ocorrência na classe dos Latossolos apenas de traços em algumas situações. Pela multiplicação da percentagem de $\mathrm{K}_{2} \mathrm{O}$ por 10 (Jackson, 1979), estimase uma participação de 29,21 e $11 \%$ de ilita na fração argila dos CX, LVA e LV, respectivamente. No 
entanto, trata-se apenas de uma participação estimada de ilita na fração argila em virtude da utilização de teores totais de $\mathrm{K}_{2} \mathrm{O}$ para o cálculo. Esses resultados parecem corroborar a maior alteração pedogenética experimentada pelos LV, comentada anteriormente.

O pico em 0,42 $\mathrm{nm}$ na argila natural refere-se ao parâmetro $110(h k l)$ da goethita, condizente com a cor amarelada dos CX. Esse "óxido" foi detectado em todos os solos, provavelmente por ser o mais estável nos equilíbrios termodinâmicos do ferro, precipitando-se em menor constante de solubilidade $\left(10^{-44}<\mathrm{Kps}<10^{-41}\right)$ (Schwertmann \& Taylor, 1989).

Os picos em 1,43, 1,13 e 1,00 nm observados nos DRX, nas direções dos ângulos com maior espaçamento, até $10^{\circ} 2 \theta$, aproximadamente, podem estar relacionados à interestratificação ao acaso da vermiculita-ilita, pela não detecção de espaçamentos regulares $(d, d / 2, d / 3, \ldots)$. Nesse caso, estima-se na interestratificação presença de aproximadamente $70 \%$ de ilita e $30 \%$ de vermiculita, cuja percentagem foi obtida pelo método de Mering (Sawhney, 1989). O mesmo tipo de interestratificação foi proposto por Almeida (1979), em que foram estimados 62 e $38 \%$ de mica e vermiculita, respectivamente.

Após os tratamentos da fração argila, foi observado um colapso da vermiculita a $1,00 \mathrm{~nm}$, com alargamento do pico onde é detectada naturalmente a ilita (Figura 3). A presença de "ombreira" característica e a maior largura do pico à meia altura com o aquecimento demonstram que o colapso foi apenas parcial na vermiculita. Isso está relacionado à presença de ilhas de Al-hidroxi nas entrecamadas de vermiculita, possivelmente formadas pela liberação de $\mathrm{Al}$ a partir da acidez dos solos com o eventual aumento na instabilidade dos aluminossilicatos (Fanning et al., 1989).

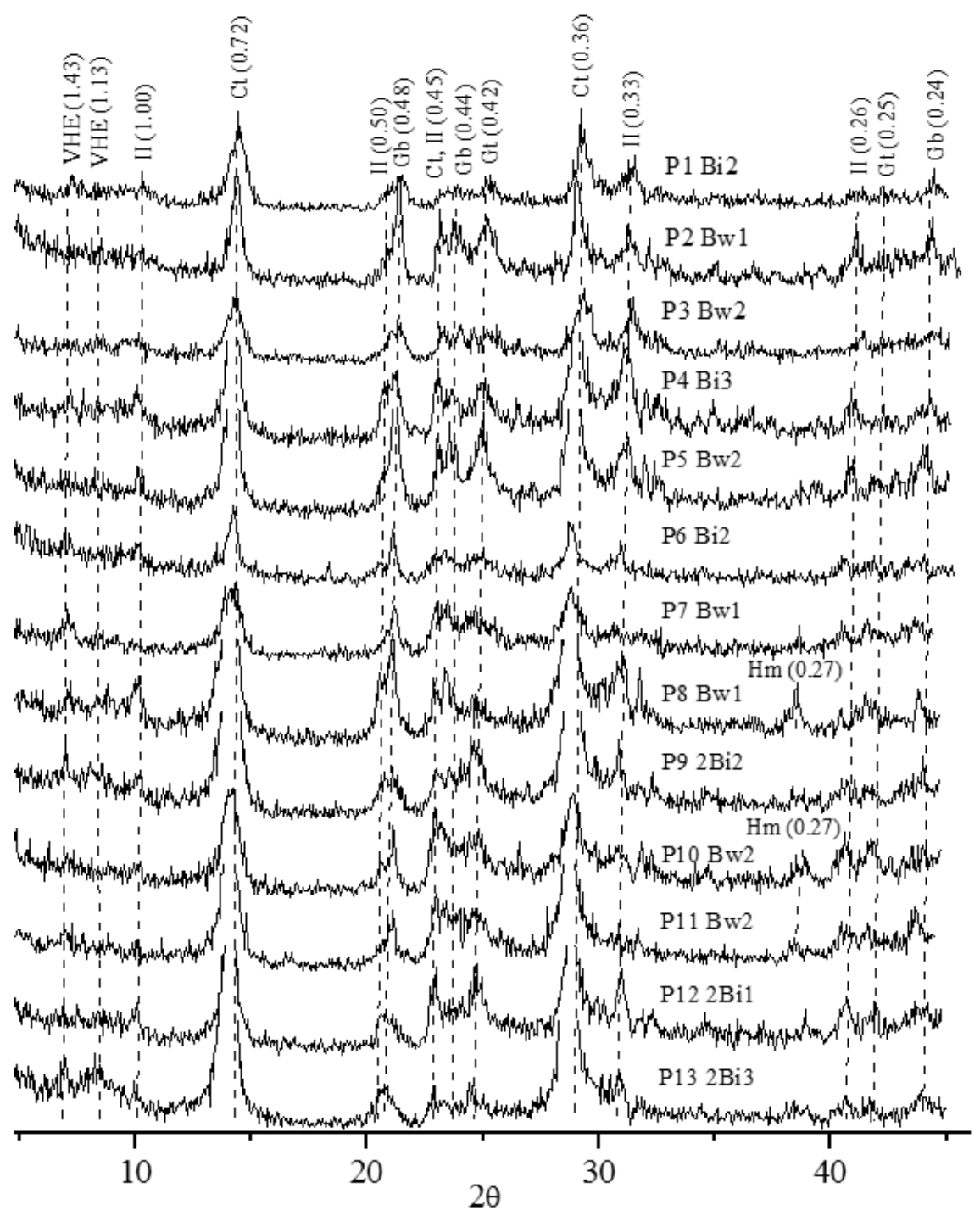

Figura 2. DRX da fração argila (horizonte B) de Latossolos e Cambissolos desenvolvidos de rochas pelíticas do Grupo Bambuí. VHE: vermiculita com Al-hidroxi entrecamadas; II: ilita; Ct: caulinita; GB: gibbsita; Gt: goethita; Hm: hematita. 
Cambissolo (P1)

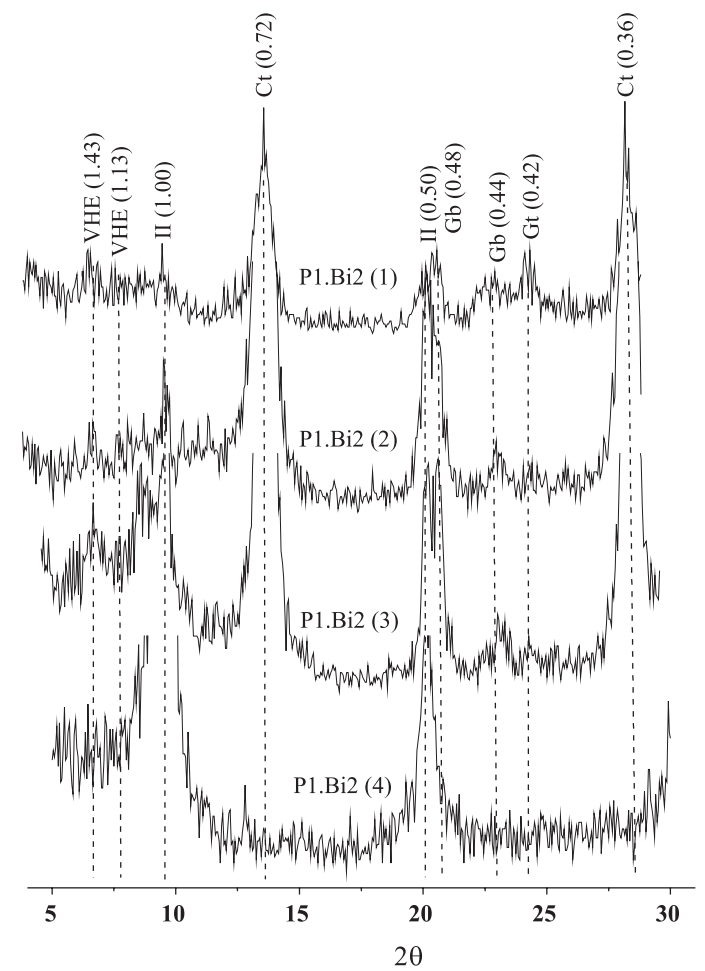

Latossolo (P8)

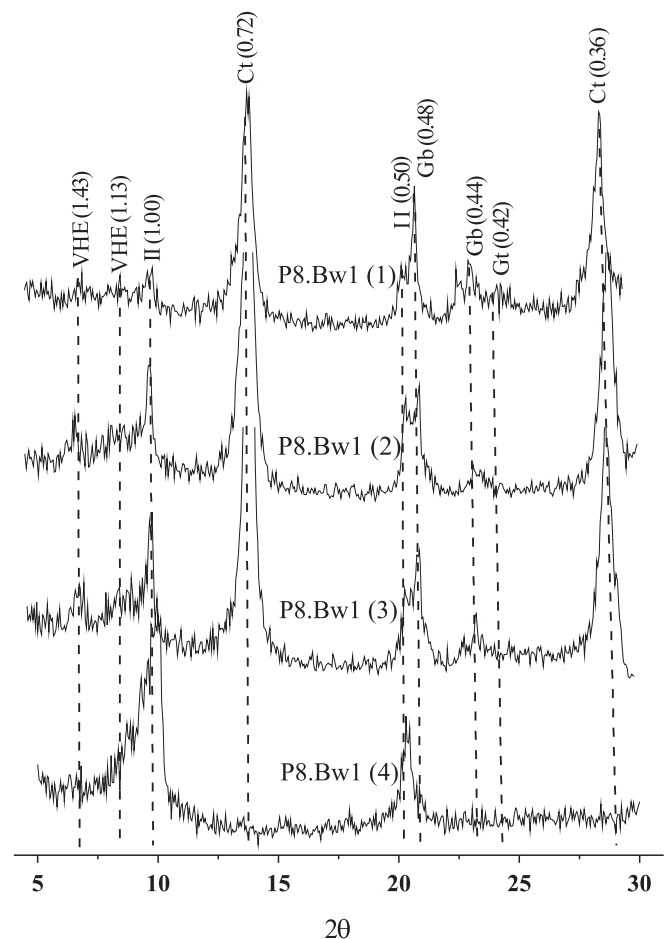

Figura 3. DRX representativos dos tratamentos realizados na fração argila dos solos estudados. VHE: vermiculita com Al-hidroxi entrecamadas; Il: ilita; Ct: caulinita; Gb: gibbsita; Gt: goethita. (1) argila natural; (2) desferrificação com DCB; (3) saturação com $\mathrm{KCl}$; (4) aquecimento a $550{ }^{\circ} \mathrm{C}$.

Assim, a formação dessas ilhas conferiu maior resistência à vermiculita, evitando que o colapso fosse completo, uma vez que vermiculitas sem esses materiais entrecamadas colapsam mais intensamente (Ker, 1988; Resende et al., 2005). Nesse caso, a ocorrência de VHE pode ser justificada pela capacidade de as ilhas de Al-hidroxi configurarem maior estabilidade aos argilominerais 2:1, termodinamicamente instáveis nas condições do meio.

Picos em 0,48 e 0,44 $\mathrm{nm}$ indicam presença de gibbsita em todos os solos, comprovada pelos desaparecimentos destes após aquecimento das amostras a $550{ }^{\circ} \mathrm{C}$ (Figura 3). É sugestivo que, nos Latossolos, resultados de Ki em torno de 1,4, associados aos DRX, indiquem que a ocorrência de gibbsita seja maior do que nos CX. Isso evidencia coexistência de VHE, ilita e gibbsita, fato pouco comum em solos menos alterados, principalmente. O mesmo foi observado por Almeida (1979), o qual atribuiu essa coexistência ao maior tamanho das partículas de mica, com menor taxa de decomposição e liberação de sílica no sistema. Nesse caso, provavelmente os baixos teores de $\mathrm{Ca}$ e $\mathrm{Mg}$ das rochas pelíticas, com maior relação $\mathrm{K} / \mathrm{Al}^{1 / 3}$ em solução (atividade), resultam na diminuição da saída de K nas entrecamadas desses aluminossilicatos (Resende et al., 2005). Somados a isso, características como a acidez dos solos, altos teores de $\mathrm{Al}$ e a possibilidade de o quartzo ser controlador da atividade de sílica em solução (mineral dominante nas frações silte e areia), provavelmente, são fatores que favorecem a formação de gibbsita mesmo em ambiente de mineralogia caulinítica/ilítica e de Ki mais elevado (CX). Assim, pode-se afirmar que a presença de gibbsita, nessa situação, não é boa indicadora de intemperização acentuada e tampouco responsável pela formação de estrutura granular, ausente nos CX e LVA.

$\mathrm{O}$ pico em $0,27 \mathrm{~nm}$ confirma a presença de hematita para os Latossolos Vermelhos (Figura 2), sendo estes os que apresentaram os maiores teores de $\mathrm{Fe}_{2} \mathrm{O}_{3}$ (digestão sulfúrica e total), em média, entre todos os que foram estudados.

A mineralogia da fração silte observada nos resultados de DRX parece refletir um pouco a litologia da região (Figura 4). Foram observados picos em 0,43 , 0,34 e $0,25 \mathrm{~nm}$ referentes ao quartzo, considerado o mineral dominante nesta fração. Os picos em 0,72, 0,45 e $0,36 \mathrm{~nm}$ referem-se à caulinita. É possível que os primeiros estádios de alteração da mica nesta fração tenham contribuído para a ocorrência dos picos nessas posições.

Picos em 1,00, 0,50, 0,45 e 0,26 nm referem-se à muscovita. A natureza placoide deste mineral, capaz de ajustar-se horizontalmente, e sua presença nos solos com elevados teores de silte, principalmente nos CX, 
são fatores que parecem interferir na qualidade física dos solos, conforme discutido. Em relação aos $\mathrm{K}$ feldspatos $(\mathrm{d}=0,24$ e $0,30 \mathrm{~nm})$ e plagioclásio $(\mathrm{d}=$ $0,32 \mathrm{~nm}$ ), suas ocorrências foram apenas de traços, evidenciando a maior capacidade de alteração desses minerais, em comparação com a muscovita e o quartzo. Nesse caso, a maior alteração dos feldspatos, que pode ser direta para gibbsita, também contribui para justificar a coexistência de gibbsita/ilita.

Na fração areia, foi detectado quase que exclusivamente o mineral quartzo, confirmando a pobreza das fontes de reserva de nutrientes nas frações grosseiras dos solos estudados (Figura 4). Nos LV, os picos em 0,27 (104) e 0,252 (110) nm confirmam a presença de hematita (nódulos e, ou, concreções) na fração areia. $\mathrm{O}$ pico $0,252 \mathrm{~nm}$ refere-se, também, à magnetita, confirmando a significativa atração magnética apresentada pelos nódulos e, ou, concreções de Fe constituintes da fração areia dos perfis P8 e, principalmente, P10. A possibilidade de a magnetita alterar-se diretamente para minerais antiferromagnéticos, provavelmente hematita (Fontes et al., 2000), parece aplicável aos LV magnéticos deste trabalho, pela não detecção de maghemita nos resultados de DRX da fração argila.

Resultados do ditionito-citrato-bicarbonato (DCB) e oxalato ácido obtidos por extrações desses nódulos e, ou, concreções revelam predomínio das formas cristalinas de Fe somente nos materiais não magnéticos, cuja relação $\mathrm{Fe}_{\mathrm{o}} / \mathrm{Fe}_{\mathrm{d}}$ foi de 0,01 (Quadro 4). De acordo com Schaefer et al. (2008), resultados dessa relação menores que 0,03 encontrados em Latossolos foram suficientes para indicar o predomínio de formas cristalinas dos óxidos de Fe. Kostka \& Luther (1994) e Reyes \& Torrent (1997) apontam que o $\mathrm{Fe}^{2+} \mathrm{da}$ magnetita catalisa a reação do oxalato, que é capaz de dissolver muito facilmente a própria magnetita, bem como parte dos outros óxidos de Fe cristalinos (Hm, $\mathrm{Gt}, . .$.$) , que na ausência do \mathrm{Fe}^{2+}$ dissolveriam muito pouco. Nesse caso, a presença de magnetita pode contribuir para explicar a diferença da relação $\mathrm{Fe}_{\mathrm{o}} / \mathrm{Fe}_{\mathrm{d}}$ entre concreções magnéticas e não magnéticas, em torno de 0,56 e 0,01, respectivamente.

Pelo fato de a litologia da Formação Três Marias ser considerada não magnética, não era esperada a presença de minerais magnéticos no solo. Assim, parece sugestivo que a presença de magnetita esteja relacionada à contribuição de materiais provenientes das bordas do Grupo Bambuí, provavelmente do embasamento Arqueano (Supergrupo Belo Horizonte) ou até mesmo do Proterozoico (Supergrupo Espinhaço) (Viana et al., 2006). Teores de $\mathrm{Fe}$ como $\mathrm{Fe}_{2} \mathrm{O}_{3}$ (2,30 dag kg-1) e FeO (4,35 dag kg-1) constatados por Chiodi Filho et al. (2003) a partir de digestão total de ardósias próximas ao município de Curvelo também são inferiores aos teores de Fe total dos solos estudados, o que reforça a hipótese de sedimentação a partir do desmonte de superfícies mais elevadas do entorno do Grupo Bambuí. No entanto, um processo de concentração relativa em relação ao material de origem e retenção de materiais mais ricos em $\mathrm{Fe}$, com eventuais transformações pedogenéticas desses

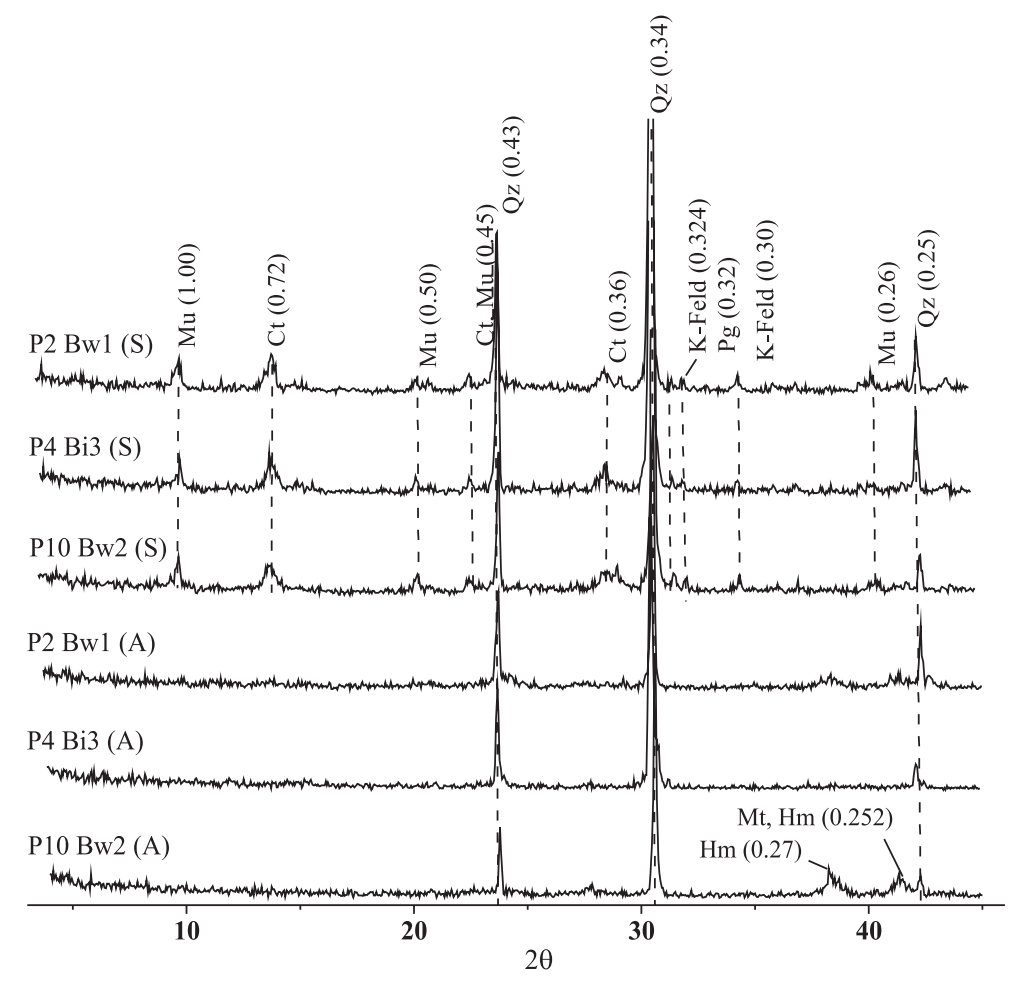

Figura 4. DRX representativos das frações silte (S) e areia (A) de LVA (P2), CX (P4) e LV (P10). Qz: quartzo; Mu: muscovita; Ct: caulinita; Pg: plagioclásio; K-Feld: feldspato potássico; Hm: hematita; Mt: magnetita. 
Quadro 4. Teores de Fe obtidos em nódulos e, ou, concreções ferruginosas por extrações com DCB e oxalato de amônio

\begin{tabular}{|c|c|c|c|}
\hline Amostra & $\underset{\Sigma^{(1)}}{\operatorname{DCB}\left(\mathrm{Fe}_{2} \mathrm{O}_{3}\right)}$ & \multirow{2}{*}{$\begin{array}{l}\text { Oxalato } \\
\left(\mathrm{Fe}_{2} \mathrm{O}_{3}\right)\end{array}$} & \multirow{2}{*}{$\frac{\mathrm{Fe}_{\mathrm{o}}}{\mathrm{Fe}_{\mathrm{d}}}$} \\
\hline & - dag & & \\
\hline \multicolumn{4}{|c|}{ P8 - Latossolo Vermelho distrófico típico } \\
\hline $\mathrm{M}^{(2)}$ & 45,71 & 23,05 & 0,50 \\
\hline $\mathrm{NM}(3)$ & 40,35 & 0,43 & 0,01 \\
\hline \multicolumn{4}{|c|}{ P10 - Latossolo Vermelho distroférrico típico } \\
\hline $\mathrm{M}^{(2)}$ & 44,52 & 28,14 & 0,63 \\
\hline $\mathrm{NM}(3)$ & 38,39 & 0,41 & 0,01 \\
\hline \multicolumn{4}{|c|}{ Extra - Latossolo Vermelho distrófico típico } \\
\hline $\mathrm{M}^{(2)}$ & 33,23 & 18,24 & 0,55 \\
\hline
\end{tabular}

precursores ferruginosos do solo a partir de queimadas da vegetação nativa, foi apontado por Viana et al. (2006) como outra hipótese para a presença de maiores teores de Fe e magnetita em Latossolos Vermelhos do Grupo Bambuí.

\section{CONCLUSÕES}

1. A mineralogia da fração argila e o índice Ki dos CX indicam menor desenvolvimento pedogenético e maior proporção de caulinita e ilita na fração argila (comparativamente aos Latossolos), que coexistem com gibbsita e VHE. A fração silte revelou presença principalmente de mica e quartzo; e a fração areia, basicamente quartzo, confirmando a baixa reserva de nutrientes nas frações grosseiras.

2. Nos CX, os elevados teores de silte associados à possibilidade de ajuste face a face do par caulinita/ ilita, possivelmente, são os principais fatores que interferem na quase ausência de organização estrutural, adensamento, fraca percolação de água e formação de selamento superficial.

3. Na fração argila dos Latossolos foi constatada coexistência de argilominerais e óxidos de $\mathrm{Fe}$ e $\mathrm{Al}$ muito semelhante à encontrada para os CX, com menores proporções de ilita e maiores de gibbsita, inferidas pelos resultados do Ki em torno de 1,4. A fração silte revelou presença principalmente de quartzo e mica; e a fração areia, basicamente de quartzo.

4. Ainda que não haja diferenciações químicas e físicas marcantes entre os Latossolos, constatou-se nos LV magnetização considerável na fração areia, cuja difratometria de raios X confirmou a presença de magnetita, apesar de este mineral estar ausente nas rochas pelíticas do Grupo Bambuí.

\section{AGRADECIMENTOS}

À FAPEMIG, pelo apoio financeiro; ao Departamento de Solos/UFV, pela possibilidade de realização do trabalho; e à V\&M Florestal - Curvelo (MG), pelo apoio aos trabalhos de coleta de solos.

\section{LITERATURA CITADA}

ACHÁ PANOSO, L.; SANTANA, D.P.; BARUQUI, A.M.; BARUQUI, F.M.; ALMEIDA, J.R.; FERREIRA, M.B. \& SOUZA, C.C. Levantamento de reconhecimento detalhado dos solos da área sob a influência do reservatório de Três Marias. Belo Horizonte, EPAMIG, 1978. 236p. (Boletim Técnico SNLCS, 57)

ALMEIDA, J.R. Cronocromossequência de solos originários de rochas pelíticas do Grupo Bambuí. Viçosa, MG, Universidade Federal de Viçosa, 1979. 150p. (Tese de Mestrado)

CHIODI FILHO, C.; RODRIGUES, E.P. \& ARTUR, A.C. Ardósias de Minas Gerais, Brasil: Características geológicas, petrográficas e químicas. Geociências, 22:119127,2003

SUPERINTENDÊNCIA REGIONAL DE BELO HORIZONTE - CPRM. Projeto Mapas Metalogenéticos e de Previsão de Recursos Minerais. Folha SE.23 - Z.A - Curvelo. Belo Horizonte, 1984. 45p.

EMPRESA BRASILEIRA DE PESQUISA AGROPECUÁRIA EMBRAPA. Centro Nacional de Pesquisa de Solos. Manual de métodos de análise de solo. 2.ed. Rio de Janeiro, Embrapa Solos, 1997. 212p.

EMPRESA BRASILEIRA DE PESQUISA AGROPECUÁRIA EMBRAPA. Centro Nacional de Pesquisa de Solos. Sistema brasileiro de classificação de solos. 2.ed. Rio de Janeiro, Embrapa Solos, 2006. 306p.

EPA 3052. Microwave assisted acid digestion of siliceous and organically based matrices. Washington, 1996. CD ROM

ERNANI, P.R.; ALMEIDA, J.A. \& SANTOS, F.C. Potássio. In: NOVAIS, R.F.; ALVAREZ V., V.H.; BARROS, N.F.; FONTES, R.L.F.; CANTARUTTI, R.B. \& NEVES, J.C.L., eds. Fertilidade do solo. Viçosa, MG, Sociedade Brasileira de Ciência do Solo, 2007. p.551-594.

FANNING, D.S.; KERAMIDAS, V.Z. \& EL-DESOKY, M.A. Micas. In: DIXON, J.B. \& WEED, S.B., eds. Minerals in soil environments. 2.ed. Madison, Soil Science Society of America, 1989. p.551-634.

FONTES, M.P.F.; OLIVEIRA, T.S.; COSTA, L.M. \& CAMPOS, A.A.G. Magnetic separation and evaluation of magnetization of Brazilian soils from different parent materials. Geoderma, 96:81-99, 2000.

JACKSON, M.L. Clay transformation in soil genesis during the quaternary. Soil Sci., 99:15-22, 1964. 
JACKSON, M.L. Soil chemical analysis: Advanced course. Madison, Prentice-Hall, 1979. 895p.

KER, J.C. Caracterização química, física, mineralógica e micromorfológica de solos brunos subtropicais. Viçosa, MG, Universidade Federal de Viçosa, 1988. 149p. (Tese de Mestrado)

KING, L.C. A geomorfologia do Brasil Oriental. R. Bras. Geogr., 18:147-265, 1956.

KORNDÖRFER, H.S.P. \& NOLLA, A. Análise de silício no solo, planta e fertilizante. Uberlândia, Universidade Federal de Uberlândia, 2004. 32p.

KOSTKA, J.E. \& LUTHER, G.W. Partitioning and speciation of solid phase iron in saltmarsh sediments. Geochim. Cosmochim. Acta, 58:1701-1710, 1994.

LADO, M. \& BEN-HUR, M. Soil mineralogy effects on seal formation, runoff and soil loss. Applied Clay Sci., 24:209$224,2004$.

MCKEAGUE, J.A. \& DAY, J.H. Dithionite and oxalate extractable $\mathrm{Fe}$ and $\mathrm{Al}$ as aids in differentiating various classes of soils. Canadian Journal of Soil Science, 46:13$22,1966$.

MARTIN, H.W. \& SPARKS, D.L. Kinetics of nonexchangeable potassium release from two costal plain soils. Soil Sci. Soc. Am. J., 47:885-887, 1983.

MEHRA, J.P. \& JACKSON, M.L. Iron oxides removal from soils and clays by a dithionite-citrate-bicarbonate system buffered with sodium bicarbonate. Clay Miner., 7:317327,1960 .

MELO, V.F. Potássio e magnésio em minerais de solos e relação entre propriedades da caulinita com formas não-trocáveis destes nutrientes. Viçosa, MG, Universidade Federal de Viçosa, 1998. 205p. (Tese de Doutorado)

MERMUT, A.R.; LUK, S.H.; ROMKENS, M.J.M. \& POESEN, J.W.A. Micromorphological and mineralogical components of surface sealing in loess soils from different geographic regions. Geoderma, 66:71-84, 1995.

NEVES, B.B.B. \& ALKIMIN, F.F. Cráton: Evolução de um conceito. In: SIMPÓSIO SOBRE O CRÁTON DO SÃO FRANCISCO, 2., Salvador, 1993. Anais. Salvador, SBG/ SGM/CNPq, 1993. p.1-10

RESENDE, M.; CURI, N.; KER, J.C. \& REZENDE, S.B. Mineralogia de solos brasileiros: Interpretação e aplicações. Lavras, Universidade Federal de Lavras, 2005. $192 \mathrm{p}$.
REYES, I. \& TORRENT, J. Citrate-Ascorbate as a highly selective extractant for poorly crystalline iron oxides. Soil Sci. Soc. Am. J., 61:1647-1654, 1997.

RODRIGUES NETTO A. Influência da mineralogia da fração argila sobre propriedades físico-químicas de solos brasileiros. Viçosa, MG, Universidade Federal de Viçosa, 1996. (Tese de Mestrado)

RUIZ, H.A. Incremento da exatidão da análise granulométrica do solo por meio da coleta da suspensão (site + argila). $\mathrm{R}$. Bras. Ci. Solo, 29:297-300, 2005.

SANTOS, R.D.; LEMOS, R.C.; SANTOS, H.G.; KER, J.C. \& ANJOS, L.H.C. Manual de descrição e coleta de solo no campo. 5.ed. Viçosa, MG, Sociedade Brasileira de Ciência do Solo, 2005. 100p.

SAWHNEY, B.L. Interstratification in layer silicates. In: DIXON, J.B. \& WEED, S.B., eds. Minerals in soil environments. 2.ed. Madison, Soil Science Society of America, 1989. p.789-824.

SCHAEFER, C.E.G.R.; FABRIS, J.D. \& KER, J.C. Minerals in the clay fraction of Brazilian Latosols (Oxisols): A review. Clay Miner., 43:137-154, 2008.

SCHWERTMANN, U. \& TAYLOR, R.M. Iron oxides. In: DIXON, J.B. \& WEED, S.B., eds. Minerals in soil environments. 2.ed. Madison, Soil Science Society of America, 1989. p.789-824.

SPARKS, D.L. Potassium dynamics in soils. New York, Springer-Verlag, 1987. 63p. (Advances in Soil Science, 6)

SPARKS, D.L. \& HUANG, P.M. Physical chemistry of soil potassium. In: MUNSON, R.D., ed. Potassium in agriculture. Madison, Soil Science Society of America, 1985. p.201-276.

STRAHLER, A. \& STRAHLER, A.N. Physical geography: Science and systems of the human environment. 2.ed. New York, John Wiley \& Sons, 2002. 748p.

VIANA, J.H.M.; COUCEIRO, P.R.C.; PEREIRA, M.C.; FABRIS, J.D.; FERNANDES FILHO, E.I.; SCHAEFER, C.E.G.R.; RECHENBERG, H.R.; ABRAHÃO, W.A.P. \& MANTOVANI, E.C. Occurrence of magnetite in the sand fraction of an Oxisol in the Brazilian savanna ecosystem, developed from a magnetite-free litology. Australian Journal of Soil Research, 44:71-83, 2006.

YEOMANS, J.C. \& BREMNER, J.M. A rapid and precise method for routine dertermination of organic carbon in soil. Comm. Soil Sci. Plant Anal., 19:1467-1476, 1988. 